\title{
EFEITO DAS FIBRAS DOS FARELOS DE TRIGO E AVEIA SOBRE O PERFIL LIPÍDICO NO SANGUE DE RATOS (Rattus norvegicus) WISTAR ${ }^{1}$
}

\author{
MARCELO AUGUSTO MENDES DA SILVA ${ }^{2}$ \\ MARIA DE FÁTIMA PÍCCOLO BARCELOS ${ }^{3}$ \\ RAIMUNDO VICENTE DE SOUSA ${ }^{4}$ \\ HESSEL MARANI LIMA ${ }^{5}$ \\ IZABELA RODARTE FALCO ${ }^{6}$ \\ ANDRELISA LINA DE LIMA ${ }^{7}$ \\ MICHEL CARDOSO DE ANGELIS PEREIRA ${ }^{8}$
}

RESUMO - Com o objetivo de determinar os efeitos das fontes de fibras de farelo de aveia e trigo sobre o perfil lipídico no sangue de ratos (Rattus norvegicus) wistar, conduziu-se este ensaio utilizando-se 48 animais, os quais foram distribuídos em um delineamento ao acaso e divididos em oito grupos. Durante um período de seis dias, os animais receberam dietas padrão para se adaptarem ao experimento. Após esse período, os animais receberam dietas distintas por 63 dias, sendo elas compostas com 5, 10 e $15 \%$ de farelo de aveia e $1 \%$ de colesterol e outras três compostas por 5,10 e $15 \%$ de farelo de trigo como fonte de fibra e $1 \%$ de colesterol. Havia dois grupos-controle, sendo o primeiro isento de colesterol e com $5 \%$ de celulose como fonte de fibra e o segundo com $1 \%$ de colesterol. Após os 63 dias recebendo as dietas experimentais, os animais se submeteram às mesmas análises de colesterol, HDL, LDL, VLDL e triacilglicerol no sangue. Os ratos ali- mentados com farelo de aveia 5, 10 e $15 \%$ tiveram redução significativa do colesterol sérico em relação ao grupo controle contendo $1 \%$ de colesterol e aos alimentados com $1 \%$ de colesterol. Os níveis de HDL foram maiores nos grupos alimentados com 10 e $15 \%$ do farelo de aveia do que nos grupos alimentados com $5 \%$ de farelo de aveia e com farelo de trigo a 5,10 e $15 \%$. Não houve diferença estatística em relação ao grupo controle e os alimentados com farelo de aveia 10 e $15 \%$. A concentração de LDL apresentou-se menor no tratamento com $15 \%$ em relação ao controle contendo colesterol e aos tratamentos com farelo de trigo. Já o os níveis de triacilglicerol e VLDL foram significativamente menores nos animais alimentados com $15 \%$ dos farelos de aveia e trigo em relação a todos os outros tratamentos. Conclui-se, neste experimento, que o perfil lipídico pode ser melhorado com a adição do farelo de aveia à dieta e que o farelo de trigo exerce pouca influência apenas nos níveis de triacilglicerol séricos.

TERMOS PARA INDEXAÇÃO: Farelo de trigo, farelo de aveia, colesterol, ratos.

\section{EFFECT OF WHEAT AND OAT BRAN FIBERS ON THE LIPID PROFILE OF MOUSE (Rattus novergicus) WISTAR BLOOD SAMPLES}

\begin{abstract}
This work aimed to determine the effects of oat and wheat bran fibers on the lipid profile in the blood of wistar mouse (Rattus novergicus). This work used 48 animals, which were randomly
\end{abstract}

distributed and divided into eight groups. During a period of six days, the animals received a pattern diet for adapting to the experiment. After this period, the animals received different diets for 63 days. The diets

\footnotetext{
1. Parte da dissertação de Mestrado do primeiro autor apresentado à UNIVERSIDADE FEDERAL DE LAVRAS/ UFLA - Caixa Postal 37 - 37200-000 - Lavras, MG.

2. Mestre em Ciência dos Alimentos/UFLA; maraugmdasi@ig.com.br.

3. Professora do Departamento de Ciência dos Alimentos/UFLA.

4. Professor do Departamento de Medicina Veterinária/UFLA.

5. Doutorando em Ciência de Alimentos - DCA/UFLA.

6. Graduanda em Medicina Veterinária/UFLA.

7. Graduanda em Agronomia/UFLA.

8. Doutorando em Ciência de Alimentos - DCA/UFLA.
} 
were composed of 5,10 , and $15 \%$ of oat bran and $1 \%$ of cholesterol. Other three diests were composed of 5, 10 , and $15 \%$ of wheat bran as fiber source and $1 \%$ of cholesterol. There was two control groups, being the first exempt of cholesterol and with $5 \%$ of cellulose as fiber source, and the second having $1 \%$ of cholesterol. After 63 days feeding the experimental diets, the animals were submitted to analyses for cholesterol in the blood, HDL, LDL, VLDL, and triacylglicerol. The mice fed with oatmeal at 5, 10, and $15 \%$ presented a significant reduction of serum cholesterol relative to the control group containing $1 \%$ of cholesterol and to those fed with $1 \%$ cholesterol. The HDL levels were higher

INDEX TERMS: Wheat bran, oat bran, cholesterol, rats.

\section{INTRODUÇÃO}

Em todo o mundo, estudos mostram estreita correlação estatística entre níveis de colesterol no sangue e morte por doença coronária. Segundo dados do Ministério da Saúde, no Brasil, as doenças cardiovasculares têm sido responsáveis por 300 mil óbitos anuais e representam os maiores custos da Previdência Social, resultantes de licenças e aposentadorias. Em 1988, essas doenças causaram $15 \%$ das mortes na faixa etária de 15 a 44 anos, atingindo, assim, pessoas jovens e em plena fase produtiva. Esses dados evidenciam a magnitude do problema das doenças cardiovasculares (GOMES, 1998).

Segundo Gerhardt e Gallo (1998), a hipercolesterolemia constitui o maior fator de risco para o aparecimento de doenças coronarianas, sendo também um forte previsor de mortalidade por essas doenças (MAHAN e ESCOTT-STUMP, 1998).

Em 1999, no Encontro Anual da AACC (American Association of Cereal Chemists) em Seattle, WA, ficou estabelecida a definição da fibra alimentar como sendo "a parte remanescente da porção comestível ou de carboidratos análogos que são resistentes à digestão e à absorção no intestino delgado humano, com fermentação completa ou parcial no intestino grosso. A fibra alimentar inclui polissacarídeos, oligossacarídeos, lignina e outras substâncias associadas. A fibra alimentar promove, ao ser humano, efeitos fisiológicos benéficos, como os laxativos, atenuação do colesterol sangüíneo e/ou atenuação da glicose sangüínea" (CAMIRE, 2001).

Segundo Anderson (1987), enquanto uma dieta restrita em lipídios pode diminuir as concentrações de in groups fed with oatmeal and $15 \%$ of wheat meal than in those fed wheat meal at 5 and $10 \%$. In spite of that, there was no statistical difference relative to the control groups and those fed with oat brans. The LDL concentrations were lower in the treatments with 10 and $15 \%$ relative to the control containing cholesterol and to the treatments with wheat meal. Triacylglicerol levels were significantly lower in animals fed with $15 \%$ oatmeal and wheat meal relative to all other treatments. It follows that the lipid profile may be improved with the addition of oat bran to the diet and that wheat meal influences only the levels of serum triacylglicerol.

colesterol sérico de 5 a $10 \%$, o uso de alimentos ricos em fibra solúvel, como farelo de aveia e produtos de feijão, podem produzir uma diminuição de 20 a 30\%, devendo ser incluídos em dietas de pacientes com hipercolesterolemia.

As fibras alimentares podem ser divididas em duas categorias: fibra solúvel e fibra insolúvel, com base nas suas propriedades físicas (capacidade de retenção, absorção, adsorção de água, capacidade de troca catiônica e absorção de moléculas orgânicas) e funções fisiológicas (CORRÊA, 2000; OLIVEIRA e MARCHINI, 2000; GUTKOSKI e PEDÓ, 2000; ZARAGOZA et al., 2001).

As fibras solúveis incluem pectinas, mucilagens, beta-glicanos e algumas hemiceluloses (GUTKOSKI e PEDÓ 2000). As pectinas são encontradas principalmente em frutas e vegetais, especialmente em maçãs, cenouras e laranjas. Outras formas de fibra solúvel estão presentes nos farelo de aveia, na cevada e nas leguminosas. A influência das fibras solúveis no trato alimentar está relacionada à sua habilidade de reter água e formar géis e também ao seu papel como substrato para fermentação de bactérias colônicas (MAHAN e ESCOTT-STUMP, 1998).

Um efeito bastante estudado é o da redução dos níveis de colesterol e low density lipoprotein (LDL Lipoproteína de baixa densidade) séricos, pois sabe-se que uma diminuição em torno de $5-15 \%$ é obtida com goma guar, pectina, psilio, fibras de aveia e betaglicano, com doses de 3-15 g/dia. O efeito é mais acentuado em pessoas com elevado nível de colesterol no sangue (RUBERFROID, 1993; ANDERSON e HANNA, 1999). Foi sugerido que as fibras que baixam o nível de colesterol no sangue o fazem ligando os áci- 
dos biliares e aumentando sua excreção, exaurindo, assim, o "pool" de colesterol no soro (NEVES, 1997 e NESTLÉ NUTRITION SERVICES, 2000). Entretanto, esse é um assunto controverso, além de existirem outras explicações possíveis, como, por exemplo, a de que a viscosidade conferida pelas fibras solúveis pode interferir na absorção de lipídios. As fibras solúveis são quase completamente fermentadas no cólon, produzindo ácido graxos de cadeia curta, os quais podem inibir a síntese hepática de colesterol e incrementar a depuração de LDL-colesterol (NEVES, 1997).

Em alguns relatos, verifica-se que fibras solúveis têm importante potencial diminuidor de colesterol e deveriam ser consideradas no controle dietético da hipercolesterolemia. Alimentos que são ricos nesse tipo de fibra são comuns e fáceis de serem incorporados à dieta de um paciente (NUOVO, 1989).

Estudiosos têm recomendado aumento na ingestão de fibras na dieta, que pode advir da ingestão de grande variedade de produtos à base de grãos integrais, frutas e vegetais, inclusive leguminosas; entretanto, é impossível aumentar a fibra na dieta sem mudar também o conteúdo de gordura e proteína, uma modificação que também tem implicações sobre a saúde (MAHAN e ESCOTTSTUMP, 1998). O Instituto Nacional do Câncer do Estados Unidos recomenda uma ingestão diária de fibras da ordem de 25 a 35 g/dia, 10 a 13 g/1000 kcal. A ingestão em excesso de fibras pode interferir com a absorção de cálcio e zinco, especialmente nas crianças e nos idosos (MAHAN e ESCOTT-STUMP, 1998).

A ingestão diária de fibra deve seguir a proporção fibra insolúvel: fibra solúvel de 3:1 (MAHAN e ESCOTT-STUMP, 1998).

Farelos de cereais, tais como os de arroz, de aveia, de trigo e de milho são utilizados em grande escala na alimentação animal, mas deveriam ser também utilizados na alimentação humana, pois fornecem, além da fibra, proteínas, calorias e quantidades consideráveis de vitaminas e minerais; são de custo baixo e de fácil obtenção, pois qualquer moinho de cereais é aparelhado para o seu fornecimento. $\mathrm{O}$ que vem limitando o uso na alimentação humana é a falta do hábito alimentar e a não-preocupação com os padrões higiênicos ideais para a obtenção do farelo, (NUTRIÇÃO..., 1991; SILVA et al., 2001).

O farelo de aveia, obtido da moagem do grão de aveia, tornou-se nos últimos tempos objeto de estudos mais aprofundados em função de suas propriedades funcionais e benefícios à saúde humana, por auxiliar na redução dos níveis de colesterol do sangue (NEVES, 1997; GUTKOSKI e PEDÓ, 2000).
O farelo de aveia é constituído por cerca de $1,2 \%$ de fibra bruta, $9,7 \%$ de fibra alimentar total, sendo $3,5 \%$ constituídos por fibras solúveis e $6,2 \%$ por fibras insolúveis (GUTKOSKI e PEDÓ, 2000).

Segundo Pedó (1996), a concentração de fibra solúvel no grão de aveia é relativamente maior quando comparada com os demais cereais, sendo os componentes mais importantes os Beta-glicanos.

Vários estudos têm comprovado a eficiência do farelo de aveia na prevenção e tratamento das doenças cardiovasculares, visto que Anderson e Gustafson (1987), após oferecerem uma suplementação com farelo de aveia para oito homens hipercolesterolêmicos por dez dias, verificaram redução de $13 \%$ nos níveis de colesterol e de $14 \%$ nos níveis de LDL plasmáticos, enquanto os níveis de HDL permaneceram constantes.

$\mathrm{O}$ farelo de trigo representa o principal subproduto da moagem do trigo, constituindo-se de uma mistura heterogênea dos fragmentos dos grãos originada da camada hialina-aleurona da semente. As proteínas de melhor valor biológico, minerais e vitaminas estão concentradas no farelo, que se torna uma fonte muito rica desses nutrientes (DI LENA et al., 1997). Contudo, o valor nutritivo do farelo vai depender da sua biodisponibilidade e da digestibilidade de seus nutrientes.

$\mathrm{O}$ teor de fibra alimentar total presente no farelo de trigo encontra-se em torno de $47,31 \%$, e, desse total, o teor de fibra insolúvel cerca de $86 \%$ representam e $14 \%$ as fibras solúveis (GUTKOSKI e PEDÓ, 2000).

Em razão do alto teor de fibras insolúveis no farelo de trigo, os estudos realizados por vários pesquisadores mostram que o seu principal efeito fisiológico é conferir um aumento no peso e no volume fecal, uma vez que a maior parte das fibras insolúveis não se degrada no cólon e pode reter água dentro de uma matriz, aumentando o peso fecal úmido de 3 a $6 \mathrm{~g} / \mathrm{g}$ de fibra e ingerida na dieta facilitando a evacuação (NESTLÉ NUTRITION SERVICES, 2000).

Em virtude dos efeitos funcionais exercidos pelos alimentos que são fontes de fibras, os farelos de aveia e de trigo, no organismo, objetivou-se, com este trabalho, avaliar a composição química de alguns farelos de cereais, bem como seus efeitos sobre parâmetros lipídicos no sangue de ratos que se alimentavam de dietas contendo colesterol.

\section{MATERIAL E MÉTODOS}

$\mathrm{O}$ ensaio in vivo foi realizado no Biotério do Departamento de Medicina Veterinária e as análises 
químicas e bioquímicas, no Departamento de Ciência dos Alimentos da Universidade Federal de Lavras.

Para o ensaio "in vivo", trabalhou-se com o farelo de aveia e com o de trigo.

\section{Ensaio in vivo}

Foram utilizados, neste experimento, 48 ratos (Rattus norvegicus) albinos da linhagem Wistar com 53 dias de vida e pesando em torno de $160 \mathrm{~g}$, provenientes do Biotério da Escola de Nutrição da Universidade Federal de Ouro Preto. No período pré-experimental, os animais foram mantidos em grupos de seis ratos por gaiolas, à temperatura ambiente (cerca de $25^{\circ} \mathrm{C}$ ), com ciclo claro-escuro, tendo acesso à ração comercial Nuvilab CR1 (Nuvital Nutrientes, Ltda.) e água ad libtum. Durante seis dias antes do início do experimento, os animais foram pesados, distribuídos aleatoriamente em gaiolas individuais e receberam uma dieta de adaptação, de acordo com American Institute Nutrition, AIN. Após esse período, os 48 animais foram divididos aleatoriamente em oito grupos e receberam as dietas experimentais e água ad libtum por 63 dias.

O peso dos animais foi verificado semanalmente, e o consumo da dieta, a cada três dias. Após o período experimental, coletou-se o sangue mediante punção cardíaca. O sangue coletado passou por um processo de centrifugação durante cinco minutos, a $10.000 \mathrm{rpm}$, a fim de que se separasse o soro. O soro foi, então, congelado a $-20^{\circ} \mathrm{C}$ para posteriores análises.

Foram elaboradas oito dietas, que constituíram os tratamentos deste trabalho (Tabela 1). Foram tomadas como base as recomendações do AIN, com algumas modificações. Havia dois grupos-controle: o primeiro com $5 \%$ de celulose e isento de colesterol e o segundo contendo $5 \%$ de celulose e $1 \%$ de colesterol. Os outros grupos diferiram no tipo de farelo (aveia ou trigo) e nas concentrações de 5, 10 e $15 \%$ desses em substituição à celulose das dietas-controle. Os farelos foram adquiridos no comércio local. O colesterol utilizado foi da marca Sigma, com $95 \%$ de pureza.

TABELA 1 - Dietas experimentais oferecidas aos oito grupos de animais (ratos). UFLA - Lavras, 2002.

\begin{tabular}{lcccccccc}
\hline \multicolumn{1}{c}{ Ingredientes g/Kg } & $\mathbf{A}$ & $\mathbf{B}$ & $\mathbf{C}$ & $\mathbf{D}$ & $\mathbf{E}$ & $\mathbf{F}$ & $\mathbf{G}$ & $\mathbf{H}$ \\
\hline Amido de milho & 564,49 & 514,49 & 464,49 & 564,49 & 514,49 & 464,49 & 574,49 & 564,49 \\
Caseína (86\% de proteína)** & 150 & 150 & 150 & 150 & 150 & 150 & 150 & 150 \\
Sacarose & 100 & 100 & 100 & 100 & 100 & 100 & 100 & 100 \\
Óleo de soja & 75 & 75 & 75 & 75 & 75 & 75 & 75 & 75 \\
Colesterol & 10 & 10 & 10 & 10 & 10 & 10 & - & 10 \\
Celulose & - & - & - & - & - & - & 50 & 50 \\
Farelo de trigo (FT) & - & - & - & 50 & 100 & 150 & - & - \\
Farelo de aveia (FA) & 50 & 100 & 150 & - & - & - & - & - \\
Pré-mix mineral & 35 & 35 & 35 & 35 & 35 & 35 & 35 & 35 \\
Pré-mix vitamínico & 10 & 10 & 10 & 10 & 10 & 10 & 10 & 10 \\
L-Cistina & 3,0 & 3,0 & 3,0 & 3,0 & 3,0 & 3,0 & 3,0 & 3,0 \\
Bitartarato de colina & 2,5 & 2,5 & 2,5 & 2,5 & 2,5 & 2,5 & 2,5 & 2,5 \\
Terbutildroquinona & 0,014 & 0,014 & 0,014 & 0,014 & 0,014 & 0,014 & 0,014 & 0,014 \\
Total. & 1000 & 1000 & 1000 & 1000 & 1000 & 1000 & 1000 & 10000 \\
\hline
\end{tabular}

*Todas as dietas continham 1\% de colesterol (com exceção da dieta G) e diferenciaram pela fonte e concentração de fibras: $A=5 \%$ de FA; $B=10 \%$ de FA; $C=15 \%$ de FA; $D=5 \%$ de FT; $E=10 \%$ de FT; $\mathrm{F}=15 \%$ de $\mathrm{FT} ; \mathrm{G}$ e $\mathrm{H}=5 \%$ de celulose.

**A proteína constituída de caseína $(86 \%)+11,6 \mathrm{~g} / 100 \mathrm{~g}$ provenientes do farelo de trigo e 22,40 g/100 g provenientes do farelo de aveia. 


\section{Análises bioquímicas}

a) Colesterol total

A dosagem de colesterol total no soro do sangue dos animais foi feita utilizando a metodologia proposta por Allain et al. (1974), utilizando-se o kit enzimático da marca In Vitro Diagnóstica (código, CAT.: 10552), conforme Manual... ([19_] $]$ ).

\section{b) HDL-colesterol}

O HDL-Colesterol foi determinado utilizando-se o kit da marca In Vitro Diagnóstica, com o sistema para precipitação de lipoproteínas, Cat: 044 do Manual... ([19_] $)$. Segundo essa metodologia, as lipoproteínas de muito baixa densidade (VLDL) e as lipoproteínas de baixa densidade (LDL) são precipitadas pelo ácido fosfotüngstico e cloreto de magnésio; após centrifugação da amostra, o colesterol ligado às lipoproteínas de alta densidade (HDL) é determinado no sobrenadante, utilizando-se a metodologia para a dosagem de colesterol total descrita anteriormente.

c) LDL-colesterol

O LDL-colesterol foi determinado de forma indireta pela fórmula:

LDL colesterol $=$ Colesterol total $-\mathrm{HDL}-$ triacilgligerol $/ 5$

Essa fórmula é citada por MAHAN e ESCOTTSTUMP (1998)

\section{d) VLDL no soro} fórmula:

Para o cálculo de VLDL no soro, utilizou-se a

$$
\text { VLDL }=\text { Triacilglicerol } / 5
$$

e) Triacilgliceróis no soro

Os triacilgliceróis foram determinados utilizando-se o kit enzimático de marca In Vitro Diagnóstica, Cat. 10724 do Manual de Produtos e Métodos (MANUAL..., [19_] $)$.

\section{Análises estatísticas}

Para as análises estatísticas dos resultados, utilizaram-se a análise de variância e o teste de Scott-Knot para a comparação dos grupos, todos a $5 \%$ de probabilidade.

Para as análises bioquímicas, o delineamento experimental foi o inteiramente ao acaso com nove tratamentos e seis repetições, com um total de 54 parcelas experimentais. Para a realização das análises estatísticas, foi utilizado o software SISVAR 4.0 (FERREIRA, 2000).

\section{RESULTADOS E DISCUSSÃO}

Na Tabela 2 encontram-se os valores séricos de colesterol total, HDL, LDL, VLDL e triacilglicerol dos diferentes grupos experimentais.

TABELA 2 - Valores médios de colesterol total, colesterol HDL, colesterol VLDL, colesterol LDL e triacilglicerol no soro sangüíneo $(\mathrm{mg} / \mathrm{dL})$ de ratos que consumiram dietas de diferentes fontes e concentrações $(5,10$ e $15 \%)$ de farelos de aveia (FA) e farelo de trigo (FT) e contendo $1 \%$ de colesterol e dois grupos-testemunha à base de celulose $(5 \%)$ sem colesterol e contendo colesterol a $1 \%$.

\begin{tabular}{|c|c|c|c|c|c|}
\hline Grupos & Colesterol* & $\begin{array}{l}\mathrm{HDL}^{*} \\
(\mathrm{mg} / \mathrm{dL})\end{array}$ & LDL* & VLDL* & Triacilglicerol* \\
\hline FA $5 \%$ & $94,72 \mathrm{c}$ & $44,25 \mathrm{~b}$ & $38,50 \mathrm{~b}$ & $11,94 \mathrm{c}$ & $59,73 \mathrm{c}$ \\
\hline FA $10 \%$ & $94,41 \mathrm{c}$ & 53,07 a & $26,69 \mathrm{~b}$ & $14,79 \mathrm{~b}$ & $73,97 \quad b$ \\
\hline FA $15 \%$ & $90,51 \mathrm{c}$ & 57,56 a & $22,24 \mathrm{c}$ & $9,67 \mathrm{~d}$ & $48,37 \mathrm{~d}$ \\
\hline FT $5 \%$ & $105,14 \mathrm{a}$ & $37,78 \mathrm{~b}$ & $49,78 \mathrm{a}$ & $16,38 \mathrm{~b}$ & $81,93 \mathrm{~b}$ \\
\hline FT $10 \%$ & $107,41 \mathrm{a}$ & $41,87 \mathrm{~b}$ & $41,69 \mathrm{~b}$ & $11,33 \mathrm{c}$ & $56,64 \mathrm{c}$ \\
\hline FT $15 \%$ & $99,04 \mathrm{~b}$ & $45,00 \mathrm{~b}$ & $38,71 \mathrm{~b}$ & $9,65 \mathrm{~d}$ & $48,37 \mathrm{~d}$ \\
\hline Controle $^{\mathrm{a}}$ & $79,99 \mathrm{~d}$ & $54,53 \mathrm{a}$ & $10,44 \mathrm{c}$ & $15,02 \mathrm{~b}$ & $75,08 \quad b$ \\
\hline Controle de colesterol $^{\mathrm{b}}$ & $97,27 \mathrm{~b}$ & $38,43 \mathrm{~b}$ & $43,10 \mathrm{~b}$ & $15,89 \mathrm{~b}$ & $79,51 \quad b$ \\
\hline C.V. $(\%)$ & 5,17 & 13,26 & 9,24 & 20,51 & 8,3 \\
\hline
\end{tabular}

$a=$ controle sem colesterol; $b=$ controle com $1 \%$ de colesterol;

*Médias de seis repetições seguidas de mesma letra não diferem $(\mathbf{p}<0,05)$ pelo teste de Scott-Knott $(1974)$ em delineamento inteiramente ao acaso. 


\section{Colesterol total}

Pode-se perceber, pela Tabela 2, que houve um aumento em torno de $21,6 \%(\mathrm{p}<0,05)$ no colesterol sérico do grupo controle ( $1 \%$ de colesterol + celulose) em relação ao grupo isento de colesterol.

Estudos realizados, que ao acrescentarem 0,3\% de colesterol nas dietas, apresentaram um pequeno aumento, mas não significativo, do colesterol sérico dos ratos.

Com relação aos efeitos dos farelos de cereais na diminuição do colesterol, o farelo de aveia mostrou-se mais efetivo no controle do colesterol do que o farelo de trigo, pois houve uma redução significativa em torno de $7 \%$ quando esse se compara com a dieta com celulose $+1 \%$ de colesterol. Entretanto, não houve diferença $(p>0,05)$ entre as concentrações $(5,10$ e $15 \%$ do farelo de aveia). Por outro lado, os resultados não se apresentaram interessantes quando se comparam as médias obtidas dos três grupos tratados com farelo de trigo, pois o máximo que se conseguiu na concentração de $15 \%$ foi igualar estatisticamente com o padrão (celulose $+1 \%$ de colesterol) e nas concentrações menores (5 e 10\%) houve até um aumento dos níveis de colesterol.

Em estudo realizado com "hamsters" alimentados com dieta com $1 \%$ de colesterol e $10 \%$ do farelo de aveia durante nove semanas, Jonnalagada et al. (1993) conseguiram verificar redução em torno de $8,5 \%$ do colesterol no soro dos animais, valor que se encontra bastante próximo do obtido neste trabalho, que foi de $7 \%$. LUPTON e YUNG (1991) demonstraram, em estudo com ratos alimentados com dietas contendo $4 \%$ de farelo de aveia, 0,18 de ácido cólico e 0,92\% de colesterol, redução de colesterol do soro em torno de $10 \%$ em relação ao grupo padrão (celulose). Nesse mesmo estudo, os autores demonstraram que mesmo aumentando para $6 \%$ a concentração de farelo de aveia e misturando farelo de trigo à dieta, não houve diferença significativa entre os tratamentos. Quando adicionou somente farelo de trigo, houve um aumento do colesterol sérico em torno de $28 \%$.

Anderson e Hanna (1999) e Costa et al. (1997) também observaram que o farelo de trigo não possui efeito na redução do colesterol sérico.

\section{HDL-colesterol}

Pode-se observar (Tabela 2) que houve uma redução significativa $(\mathrm{p}<0,05)$ do HDL de $29,5 \%$, quando se adicionou $1 \%$ de colesterol à dieta-padrão.
A concentração de HDL apresentou-se significativamente maior em relação ao padrão mais $1 \%$ de colesterol nos tratamentos com 10 e $15 \%$ de farelo de aveia, não havendo diferença significativa entre dois grupos e o grupo controle (sem colesterol). Nos três tratamentos com farelo de trigo e farelo de aveia a 5\%, os valores de HDL foram menores, sendo os tratamentos estatisticamente iguais ao grupo padrão, adicionado $1 \%$ de colesterol.

Os efeitos do farelo de aveia sobre os níveis de HDL séricos ainda não foram totalmente esclarecidos, pois autores como Anderson e Hanna (1999) verificaram que o farelo de aveia tende a diminuir suavemente essas concentrações; por outro lado, afirmam que esses efeitos ainda não estão bem delineados e que mais estudos são necessários para entender os efeitos específicos das fibras solúveis sobre a fração HDL. O trabalho realizado por Jonnalagada et al. (1993) demonstrou que os níveis de HDL se igualaram aos do grupo controle, quando era oferecido farelo de aveia aos animais (hamsters). Neves (1997) cita um trabalho realizado por Anderson e Gustafson (1987), no qual oito homens hipercolesterolêmicos receberam uma dieta suplementada com farelo de aveia durante dez dias. Constatouse, após esse período, que a média do colesterol plasmático caiu $13 \%$ em relação aos valores iniciais, enquanto LDL colesterol teve uma redução de $14 \%$ e os valores de HDL permaneceram constantes.

Bridges (1992) realizou experimento com 20 homens portadores de hipercolesterolemia e, após oferecer dieta contendo farelo de trigo a esses pacientes, perceberam que houve uma pequena redução (em torno de 4,4 $\pm 3,0 \%$ ) nos níveis de HDL.

Em contrapartida, Karla e Jood (2000) verificaram aumento da quantidade de HDL no sangue de ratos alimentados com diversas variedades de cevada. É importante salientar que a cevada, assim como a aveia, também é um cereal rico em Beta-glicano e, portanto, o mecanismo de atuação no controle lipídico é igual ao da aveia.

\section{LDL-colesterol}

Pode-se observar, pelos resultados obtidos (Tabela 2) que houve um aumento significativo ( $<<0,05)$, em torno de $312,8 \%$ de LDL do soro dos ratos alimentados com $1 \%$ de colesterol, em relação ao grupo padrão isento de colesterol. Por meio desta variável (LDL), constatou-se realmente o efeito benéfico do farelo de aveia, pois o grupo alimentado com dieta contendo $15 \%$ de farelo de aveia apresentou uma redução significativa nos teores de LDL-colesterol séricos $(p<0,05)$. 
Neste trabalho, verificou-se redução do LDL acima da média relatada por alguns autores, como Saunders (1990), que verificou redução de $11 \%$ nos níveis de LDL em ratos. Isso ocorre provavelmente pelo conteúdo de beta-glicanos existente no farelo de aveia. Essa fração da fibra solúvel é responsável pela diminuição do colesterol total e LDL. Esse efeito pode ser atribuído à adsorção de ácidos biliares após sua desconjugação pelas bactérias intestinais, sendo excretado pelas fezes, diminuindo o pool de ácidos biliares no ciclo êntero-hepático, ou aos ácidos graxos de cadeia curta, produzidos pela degradação bacteriana das fibras no cólon, os quais também inibem a síntese de colesterol hepático e incrementam a depuração de LDL (COSTA et al., 1997; NEVES, 1997).

Com relação aos resultados obtidos pelos grupos alimentados com farelo de trigo, observou-se que não houve redução dos níveis séricos de LDL do sangue dos animais experimentais e que, quando o teor de fibras era menor, ou seja, no grupo com $5 \%$ do farelo de trigo, os níveis até aumentaram. Esses valores encontrados comprovam resultados revisados por Costa et al. (1997).

\section{VLDL-colesterol}

Pode-se observar, na Tabela 2, que os níveis de VLDL apresentaram comportamento semelhante ao de triacilglicerol. Esse resultado já era esperado, visto que as VLDLs são as principais transportadores de triacilglicerol endógenos, e um foi calculado a partir do outro, portanto, conforme Duarte (1996), a redução dos níveis de triacilglicerol implica na redução dos níveis de VLDL. Parece ter ocorrido comportamento semelhante, ou seja, as dietas com $15 \%$ de farelo de aveia e farelo de trigo proporcionaram reduções significativas $(\mathrm{p}<0,05)$ nos níveis de VLDL.

Acredita-se que a grande partícula de VLDL "flutuante" seja não-aterogênica, mas as partículas remanescentes de VLDL, denominadas IDL, podem ser capturadas pelo fígado ou ser transformadas em LDL, tornando-se aterogênicas. Contudo, dietas com um alto teor de colesterol podem levar ao aumento dessas partículas remanescentes. Por outro lado, dietas vegetarianas podem levar ao aumento das "grandes" partículas de VLDL (não-aterogênica) (MAHAN e ESCOTT-STUMP, 1998).

\section{Triacilglicerol}

A adição de colesterol na dieta, conforme Tabela 2 , não aumentou significativamente o nível de triacilglicerol sérico quando comparado ao grupo padrão isento de colesterol. Resultados semelhantes foram encontrados por Anderson et al. (1994). Também houve uma redução significativa do triacilglicerol dos tratamentos com farelo de aveia a $5 \%$ e farelo de trigo a $10 \%$.

Duarte (1996) também registrou resultados semelhantes na diferença entre o grupo padrão sem adição de colesterol e o controle ( $1 \%$ de colesterol $+0,1 \%$ de ácido cólico), ou seja, uma redução de cerca de $16 \%$ do triacilglicerol sanguiíneo dos ratos do primeiro grupo (padrão) e do segundo (controle).

Como pode ser observado (Tabela 2), tanto o farelo de aveia (15\%) quanto o farelo de trigo (15\%) proporcionaram os melhores resultados, não sendo estatisticamente diferentes entre si. A redução observada pelos dois tratamentos foi de $38,45 \%$ ( $\mathrm{p}<0,05)$ em relação ao padrão (celulose $+1 \%$ de colesterol). Anderson e Hanna (1999), após realizarem uma revisão neste assunto, constataram que em alguns trabalhos realizados com farelo de trigo houve uma redução média de $38 \%$ nos níveis de triacilglicerol. Nesse mesmo estudo, verificaram que a redução média de triacilglicerol pelo consumo de farelo de aveia era da ordem de $13,4 \%$.

Essa diminuição observada do triacilglicerol ocorre pelo fato de fibras solúveis provocarem retardo no esvaziamento gástrico, o que pode levar a uma diminuição nos níveis de triacilglicerol após refeições gordurosas. As fibras podem agir diminuindo a absorção intestinal de triglicérides, provocando pequeno aumento na quantidade de gordura fecal e contribuindo para reduzir os níveis de triacilgliceróis séricos (COSTA et al., 1997).

Por outro lado, parece que as fibras insolúveis, por diminuírem o tempo de trânsito intestinal, diminuem a absorção de gorduras, podendo diminuir os níveis de triacilglicerol séricos (RAUPP, 1994).

\section{CONCLUSÕES}

O farelo de aveia utilizado como fonte de fibra nos três níveis mudou o perfil lipídico dos animais, pois houve uma redução do colesterol total, LDL e triacilglicerol sérico e aumento dos níveis de HDL séricos.

$\mathrm{O}$ farelo de trigo exerceu efeito positivo somente sobre os níveis de triacilglicerol sérico dos ratos. 


\section{REFERÊNCIAS BLIOGRÁFICAS}

ANDERSON, J. W.; HANNA, T. J. Impact of nondigestible carbohydrates on serum lipoproteins and risk for cardiovascular disease. Journal of Nutrition, Kentuchy, v. 129, p. 1475S-1466s, 1999.

ANDERSON, J. W.; GUSTAFSON, N. J. Dietary fiber in desease prevention an treatment. Comprehensive Therapy, Skokie, v. 13, n. 1, p. 43-53, 1987.

ANDERSON, J. W. Dietary fiber, lipidis and atherosclerosis. The American Journal of Cardiology, New York, v. 60, p. 17-22, 1987.

ANDERSON, J. W.; JONES, A. M.; RIDDELMASON, S. Tem defferent dietary fibers have significantly differente effect on serum na liver lipids of cholesterol-fed rats. Journal of Nutrition, Philadelphia, v. 124, p. 78-73, 1994

ALLAIN, C. C.; POON, L. S.; CHAN, C. S.; RICHMOND, W.; FU, P. C.; Enzimatic determination of total serum cholesterol. Clinical Chemical, Washington, v. 20, n. 4, p. 470-475, 1974.

BRIDGES, S. R. Oat bran increases serum acetate of hipercholesterolemic men. American Journal of Clinical Nutrition, New York, v. 56, p. 455-459, 1992.

CAMIRE, M. E. The definition of dietary fiber. Cereal foods world, Minneapolis, v. 46, n. 3, p. 112-124, Mar. 2001.

CORRÊA, A. D. Farinha de folhas de mandioca: efeitos de processamentos sobre alguns nutrientes e antinutrientes. 2000. 108 p. Tese (Doutorado Ciência dos Alimentos) - Universidade Federal de Lavras, Lavras, 2000 .

COSTA, R. P.; SILVA, C. C.; MAGNONI, C. D. Importância das fibras na prevenção de doenças cardiovasculares. Revista Brasileira de Nutrição Clínica, São Paulo, v. 12, p. 151-154, 1997.

DI LENA, G.; PATRONI, E.; QUAGLIA, G. B. Improving the nutritional value of wheat bran by a whiterot fungs. International Journal of food science and technology, Oxford, v. 32, p. 513-519, 1997.
DUARTE, H. S. Elaboração e Avaliação de um alimento formulado em pó rico em fibra no controle da hipercolesterolemia. Viçosa: UFV, 1996. 137 p.

FERREIRA, D. F. Análises estatísticas por meio do Sisvar para Windows versão 4.0. In: REUNIÃO AUNAL DA REGIÃO BRASILEIRA DA SOCIEDADE INTERNACIONAL DE BIOMETRIA, 2000, São Carlos. Anais... São Carlos: UFSCar, 2000. p. 255-258.

GERHARDT, A. L.; GALLO, N. B. Full-fat rice bran and oat bran similary reduce hypercolesterolemia in humans. Journal of Nutrition, Sacramento, v. 128, p. 865-869, 1998.

GOMES, S. I. M. Efeitos dos flavonóides no metabolismo lipídico. 1998. 95 f. Dissertação (Mestrado) Universidade Federal de Viçosa, Viçosa, 1998.

GUTKOSKI, L. C.; PEDÓ, I. Aveia: composição química, valor nutricional e processamento. São Paulo: Varela, 2000. 191 p.

JONNALAGADA, S. S.; THYE, F. W.; ROBERTSON, J. L. Plasma total na lipoprotein cholesterol, liver cholesterol and fecal cholesterol excretion in hamsters fed fiber diets. Jounal of Nutrition, Philadelphia, v. 123, p. 1377-1382, 1993.

KARLA, S.; JOOD, S. Efect of dietary Barley betaglucan o cholesterol and Lipoprotein Fractions in Rats. Journal of Cereal Science, London, v. 31, p. 141-145, 2000.

LUPTON, J. R.; YUNG, K. Y. Interactive effects of oat bran and wheat bran on serum and liver lipids and colonic physiology. Cereal Foods World, Minneapolis, v. 36, n. 9, Sept. 1991.

MAHAN, L. K.; SCOTT-STUMP, S. M. A. Krause alimentos, nutrição e dietoterapia. 9. ed. São Paulo: Roca, 1998. 1179 p.

MANUAL de produtos e métodos: in vitro diagnóstica. Itabira: [s.n.], [19__]. 110 p.

NESTLÉ NUTRITION SERVICES. Tópicos em nutrição clínica: fibras em nutrição enteral, questões contemporâneas. [S.1.], 2000. 27 p. 
NEVES, N. M. S. Nutrição e doença cardiovascular. Rio de Janeiro: Guanabara Koogan, 1997. 109 p.

NUOVO, J. Use of dietary fiber to lower cholesterol. A. F. P., [S.1.], v. 39, p. 137-140, 1989.

NUTRIÇÃO é do bicho homem... e o bicho come. Globo Rural, São Paulo, n. 67, p. 51-55, maio 1991.

OLIVEIRA, J. E. D. de; MARCHINI, S. J. Ciências nutricionais. São Paulo: Sarvier, 2000. 403 p.

PEDÓ, I. Caracterização química e nutricional de novos cultivares de aveia (Avena sativa, L.). 1996. Dissertação (Mestrado) - Faculdade de Engenharia de Alimentos, Universidade Estadual de Campinas, Campinas, 1996.

RAUPP, D. S. Caracterização nutricional da fibra alimentar solúvel e insolúvel do feijão "carioca 80 SH" em dietas experimentais com ratos. 1994. Tese (Doutorado) - Faculdade de Engenharia de Alimentos, Universidade Estadual de Campinas, Campinas, 1994.
RUBERFROID, M. Dietary fiber, inulin and oligofrutose: a revewcomparing their phisiological efects. Critical Review of Food Science Nutrition, Boca Raton, v. 33, n. 6, p. 1303-1348, 1993.

SAUNDERS, R. M. The properties of rice bran as a foodstuff. Cereal foods world, Minneapolis, v. 35, n. 7, p. 633-636, July 1990.

SCOTT, A. J.; KNOTT, M. A. A cluster analysis method for grouping means in the analysis of variance. Biometrics, Washington, v. 30, n. 3, p. 507-512, Sept. 1974.

SILVA, M. A.; SANCHES, C.; AMANTE, E. R. Farelo de arroz composição e propriedades. Óleos \& Grãos, São Bernardo do Campo, p. 34-42, jul./ago. 2001.

ZARAGOZA, M. Z.; PÉREZ, M. R.; NAVARRO, Y. T. G. Propriedades funcionales y metodología para su evaluación en fibra dietética. In: Fibra dietética en Iberoamérica: tecnología y salud. São Paulo: Varela, 2001. p. 195-209. 